Tropical Journal of Pharmaceutical Research June 2014; 13 (6): 989-995

ISSN: $1596-5996$ (print); 1596-9827 (electronic)

(C) Pharmacotherapy Group, Faculty of Pharmacy, University of Benin, Benin City, 300001 Nigeria.

All rights reserved.

Available online at http://www.tjpr.org

Original Research Article

http://dx.doi.org/10.4314/tjpr.v13i6.24

\title{
Evaluation of Adherence to Diabetic Treatment in Northern Region of United Arab Emirates
}

\author{
Fatima Koprulu ${ }^{1 *}$, Refqa JK Bader ${ }^{2}$, Nageeb AGM Hassan ${ }^{1}$, Abduelmula R \\ Abduelkarem ${ }^{3}$ and Dhafir A Mahmood ${ }^{4}$ \\ ${ }^{1}$ Department of Clinical Pharmacy, College of Pharmacy, Ajman University of Science and Technology, ${ }^{2}$ GMC AL-Noor \\ Pharmacy, Ajman, ${ }^{3}$ Department of Pharmacy Practice and Pharmacotherapeutics, College of Pharmacy, University of Sharjah, \\ Sharjah, ${ }^{4}$ Department of Endocrinology, Oriana Hospital, Sharjah, United Arab Emirates
}

*For correspondence: Email: dr.fatima.alkhalidi@gmail.com; Tel: 00971508835184

Received: 27 February 2014

Revised accepted: 27 April 2014

\begin{abstract}
Purpose: To determine medication adherence and predictors of suboptimal adherence in patients with diabetes type 2, and to address the factors that are associated with treatment non-adherence in Northern Region of United Arab Emirates (UAE).

Methods: This cross-sectional study involved 200 type 2 diabetes mellitus (T2DM) patients randomly selected from outpatient clinics in Northern Region, UAE. Special questionnaire form have been prepared to assess the level of adherence then filled in through direct interviewing with the patients. The adherence level score was calculated based on total summation of items related to good adherence and accordingly participants' scores of $90 \%$ or more were considered adherent and who achieved less than $90 \%$ were non-adherent.

Results: Only 120 (60\%) of the patients were adherent. Factors that are associated with nonadherence were :age $\geq 50$ (OR = 1.8, $95 \% \mathrm{Cl}=1.02$ - 3.19), lower education level $(\mathrm{OR}=0.17,95 \% \mathrm{Cl}$ $=0.09-0.31)$, lack of health insurance $(O R=21,95 \% \mathrm{Cl}=9.62-45.85)$, forgetfulness $(O R=0.29, \mathrm{Cl}=$ 0.13 - 0.61), co-morbidities (OR $=0.24,95 \% \mathrm{Cl}=0.11-0.51),>6.5 \% \mathrm{HbA1C}(\mathrm{OR}=7.22,95 \% \mathrm{Cl}=$ 3.69 - 14.14); longer time since last visit to clinic $(O R=14,95 \% \mathrm{Cl}=6.52-30.04)$; increased medication cost $(O R=30,95 \% \mathrm{Cl}=11.2-80.1)$; and unawareness (lack of awareness) of physician instructions $(\mathrm{OR}=7.22,95 \% \mathrm{Cl}=3.7-14.1)$.

Conclusion: Adherence to diabetes treatment was quite poor among participants. Glycemic control could be improved through early identification and incentives for adherence behaviors which can be supported using a counseling approach of communication with the patients by healthcare professionals before applying any individual patient management plan.
\end{abstract}

Keywords: Medication adherence, Type 2 diabetes, Antidiabetic, Predictors, United Arab Emirates

Tropical Journal of Pharmaceutical Research is indexed by Science Citation Index (SciSearch), Scopus, International Pharmaceutical Abstract, Chemical Abstracts, Embase, Index Copernicus, EBSCO, African Index Medicus, JournalSeek, Journal Citation Reports/Science Edition, Directory of Open Access Journals (DOAJ), African Journal Online, Bioline International, Open-J-Gate and Pharmacy Abstracts

\section{INTRODUCTION}

Diabetes mellitus is an especially common and serious medical condition in the United Arab Emirates (UAE), the country which has the second highest prevalence of diabetes worldwide (90\% of cases of diabetes are of type 2), and it is one of the International Diabetes Federation's 'top 10' countries for diabetes prevalence in 2010 and in 2030 [1]. Diabetes is believed to be one of the most psychologically and behaviourally demanding of the chronic diseases [2]. It has been reported that non-adherence to medication and lifestyle regimes in diabetes is associated with decreased treatment effectiveness, worsened medical outcomes, increased 
hospitalizations and increased health care costs [3]. Adherence refers to the extent to which a person's behavior - taking medication, following a diet, and/or executing lifestyle changes, corresponds with agreed recommendations from a health care professional [4]. Medication adherence can be challenging for individuals with diabetes due to many factors such as: disease duration, regimen complexity and understanding, cost, patient -provider relationship and patient education [5].

In the UAE, only a few studies have assessed diabetes care $[6,7]$ or evaluated adherence problems among diabetic patients [8,9], and little is known about adherence to oral hypoglycemic agent regimens in patients with type 2 diabetes across this region.

This study has been designed with aim to determine medication adherence and predictors of suboptimal adherence in a community cohort of patients with type 2 diabetes in UAE and to address the factors that are associated with the medication non adherence.

\section{EXPERIMENTAL}

\section{Study setting}

The study was conducted among diabetes type 2 patients in Northern Emirates of United Arab Emirates. The study sample was collected from five different diabetes clinics and three hospitals outpatient clinics including governmental and nongovernmental sectors in this region of the UAE.

\section{Study design}

The present work is a cross sectional study. A total of 200 participants were randomly selected to be part of the study in northern regions of the UAE, from May 2012 to April 2013. Patients who suffer from type 2 diabetes, aged over 18 years old and patients who were given written informed consent to participate in the study are included in the study. Patients with other types of diabetes, less than 18 years old, who are too ill to be interviewed and who refused to participate in the study, were excluded from the study.

The study instrument was structured questionnaire which had been developed after extensive literature review and used to collect the data. It was in a form of multiple choices questions and consisted of two parts; first part included demographic data and the second part included 15 study questions which consist of questions about treatment adherence and factors that are associated with non-adherence which are: patient-related factors, disease and therapyrelated factors and health care-related factors. The adherence level score was calculated based on total summation of items related to adherence and accordingly participants' scores of $90 \%$ or more were considered adherent and who achieved less than $90 \%$ were non-adherent. Patients of this study were interviewed after taking approval from the management of each clinic and hospital. The participation was voluntary and a written consent was acquired from each participant. Each patient was interviewed by researcher or by a specialized nurse from the clinics.

\section{Validity and reliability}

The questionnaire was piloted among 20 type 2 diabetic patients selected within the study field; these patients were subsequently excluded from the study. The purpose of the pilot study was: to test the validity and reliability of the questionnaire, check easiness of use and whether the answers would lead to achieving the set aims, in addition to testing the understanding of the interviewer and to correct mistakes. Then from the pilot study results, reliability was measured using Cronbach's alpha coefficient which showed the calculated reliability coefficient of the total score of the test (0.89) which considers as acceptable reliability to conduct the study.

To ensure the face validity of the instrument, the questionnaire was sent to three faculty members at college of pharmacy and health sciences, Ajman University of Science and Technology (AUST), to one endocrinologist, one general practitioner, and four community pharmacists with a wide range of experience within the profession. All of their views and comments were considered and then incorporated into the final version of the questionnaire.

\section{Statistical analysis}

The data was analyzed by Statistical Package for Social Science (SPSS, version 20). Descriptive statistics were used for general description of study participants and to obtain the prevalence of non- adherence to diabetes treatment. Bivariate analysis was then performed between the various independent variables and nonadherence to diabetes treatment. Odds ratio, their $95 \%$ confidence intervals and $\mathrm{P}$-values were obtained. $p<0.05$ was considered statistically significant. 


\section{RESULTS}

Table 1: Socio-demographic characteristics of respondents

\begin{tabular}{|c|c|c|}
\hline \multirow{2}{*}{ Characteristic } & \multicolumn{2}{|c|}{ Participants } \\
\hline & $\mathbf{N}$ & $\%$ \\
\hline \multicolumn{3}{|l|}{ Age } \\
\hline$<50$ & 105 & 52.5 \\
\hline$\geq 50$ & 95 & 47.5 \\
\hline \multicolumn{3}{|l|}{ Gender } \\
\hline Male & 80 & 40 \\
\hline Female & 120 & 60 \\
\hline \multicolumn{3}{|l|}{ Marital status } \\
\hline Married & 109 & 54.5 \\
\hline Single & 91 & 45.5 \\
\hline \multicolumn{3}{|l|}{ Nationality } \\
\hline UAE Citizen & 30 & 15 \\
\hline Others & 170 & 85 \\
\hline \multicolumn{3}{|c|}{ Level of education } \\
\hline None & 20 & 10 \\
\hline Primary & 60 & 30 \\
\hline Secondary & 20 & 10 \\
\hline University/tertiary & 100 & 50 \\
\hline \multicolumn{3}{|l|}{ Occupation } \\
\hline Employed & 100 & 50 \\
\hline Unemployed & 100 & 50 \\
\hline \multicolumn{3}{|c|}{ Monthly income in AED } \\
\hline$<10,000$ & 98 & 49 \\
\hline$\geq 10,000$ & 102 & 51 \\
\hline \multicolumn{3}{|l|}{ Health insurance } \\
\hline Yes & 100 & 50 \\
\hline No & 100 & 50 \\
\hline
\end{tabular}

Among the respondents 105 (52.5\%) were with age group less than 50 years. More than half pooled were female $120(60 \%)$ and were married 109 (54.5\%). During the study period, one hundred $(50 \%)$ of the patients participated in the study reported that they have university education degree. Despite the fact that half of the participants had university degree, but also half of them $(50 \%)$ were un-employed Sociodemographic characteristics are summarized in Table 1.

\section{Adherence to medication}

The overall prevalence of non-adherence was 80 (40 \%). Significant association was found between education level and non-adherence (OR $=0.17, \mathrm{Cl}=0.09-0.31$ ) where the patients who had no or primary education (75\%) had higher prevalence of non-adherence. The monthly income of the patients was had also significant association with non- adherence $(O R=0.15, \mathrm{Cl}$ $=0.08-0.29$ ) where the monthly income less than ten thousands Emirati dirham (75\%) had higher prevalence of non-adherence. Significant association with non adherence was found with health insurance $(\mathrm{OR}=21.0, \mathrm{Cl}=9.62$ - 45.85) where the participant who did not have health insurance had higher risk for non-adherence (Table 2).

Table 2: Association between adherence and demographics data

\begin{tabular}{|c|c|c|c|c|c|}
\hline \multirow[b]{2}{*}{ Variable } & \multicolumn{2}{|c|}{ Adherence } & \multirow{2}{*}{ Odds ratio } & \multirow{2}{*}{$95 \% \mathrm{Cl}$} & \multirow{2}{*}{$P$-value } \\
\hline & Yes $\{n(\%)\}$ & No $\{n(\%)\}$ & & & \\
\hline \multicolumn{6}{|l|}{ Age } \\
\hline$<50$ & $70(58.5 \%)$ & $35(43.5 \%)$ & \multirow{2}{*}{1.8} & \multirow{2}{*}{$1.02-3.19$} & \multirow{2}{*}{0.04} \\
\hline$\geq 50$ & $50(41.5 \%)$ & $45(56.5 \%)$ & & & \\
\hline \multicolumn{6}{|l|}{ Gender } \\
\hline Male & $50(41.5 \%)$ & $30(37.5 \%)$ & \multirow{2}{*}{1.19} & \multirow{2}{*}{$0.67-2.13$} & \multirow{2}{*}{0.56} \\
\hline Female & $70(58.5 \%)$ & $50(62.5 \%)$ & & & \\
\hline \multicolumn{6}{|l|}{ Marital status } \\
\hline Married & $69(57.5 \%)$ & $40(50 \%)$ & \multirow{2}{*}{1.35} & \multirow{2}{*}{$0.77-2.39$} & \multirow{2}{*}{0.39} \\
\hline single & $51(42.5 \%)$ & $40(50 \%)$ & & & \\
\hline \multicolumn{6}{|l|}{ Level of education } \\
\hline None/primary & $20(25 \%)$ & $60(75 \%)$ & \multirow{2}{*}{0.17} & \multirow{3}{*}{$0.09-0.31$} & \multirow{2}{*}{$<0.001$} \\
\hline Secondary/tertiary & $80(66.5 \%)$ & $40(33.5 \%)$ & & & \\
\hline \multicolumn{5}{|l|}{ Occupation } & \\
\hline Employed & $65(54.5 \%)$ & $35(44 \%)$ & \multirow{2}{*}{1.52} & \multirow{2}{*}{$0.86-2.68$} & \multirow{2}{*}{0.15} \\
\hline Unemployed & $55(45.5 \%)$ & $45(56 \%)$ & & & \\
\hline \multicolumn{6}{|c|}{ Monthly income in AED* } \\
\hline$<10,000$ & $38(31.5 \%)$ & $60(75 \%)$ & \multirow{2}{*}{0.15} & \multirow{2}{*}{$0.08-0.29$} & \multirow{2}{*}{$<0.001$} \\
\hline$\geq 10,000$ & $82(68.5)$ & $20(25 \%)$ & & & \\
\hline \multicolumn{6}{|l|}{ Health insurance } \\
\hline Yes & $90(75 \%)$ & $10(12.5 \%)$ & \multirow{2}{*}{21.0} & \multirow{2}{*}{$9.62-45.85$} & \multirow{2}{*}{$<0.001$} \\
\hline No & $30(25 \%)$ & $70(87.5 \%)$ & & & \\
\hline
\end{tabular}


Factors associated with non-adherence to diabetic treatment

Among patient-related factors, forgetfulness (OR $=0.29, \mathrm{Cl}=0.13-0.61$ ), last follow-up with diabetes center or clinic $(\mathrm{OR}=14.0, \mathrm{Cl}=6.52$ 30.04) where the last follow-up with diabetes clinic more than one month $(87.5 \%)$ had higher prevalence of non adherence to medications. On the other hand, the patients who had education (education session to educate the patient about their disease which are usually done by ministry of health, hospitals or diabetes centers) sessions were significantly associated with adherence and had lower risk of non-adherence session (OR = $10.39, \mathrm{Cl}=5.34-20.21)($ Table 3$)$.

As for disease and therapy-related factors, suffering from other conditions or co-morbidities $(\mathrm{OR}=0.24, \mathrm{Cl}=0.11-0.51)$, experiencing side effects $(\mathrm{OR}=0.35, \mathrm{Cl}=0.18-0.68)$,

Table 3: Frequency, Odd ratio and $95 \% \mathrm{Cl}$ of patient, health care, disease and therapy related factors

\begin{tabular}{|c|c|c|c|c|c|}
\hline \multirow[b]{2}{*}{ Variable } & \multicolumn{2}{|c|}{ Adherence } & \multirow{2}{*}{$\begin{array}{l}\text { Odds } \\
\text { ratio }\end{array}$} & \multirow[b]{2}{*}{$95 \% \mathrm{Cl}$} & \multirow[b]{2}{*}{$P$-value } \\
\hline & $\begin{array}{c}\text { Yes } \\
\text { n }\{\%\}\end{array}$ & $\begin{array}{c}\text { No } \\
n\{\%\}\end{array}$ & & & \\
\hline $\begin{array}{l}\text { Patient-related factors } \\
\text { Forget to take medications }\end{array}$ & $80(66.5)$ & $70(87.5)$ & 0.29 & $0.13-0.61$ & $<0.001$ \\
\hline $\begin{array}{l}\text { Last follow-up with diabetic centre or } \\
\text { clinic } \\
\text { Less than one month } \\
\text { More than one month }\end{array}$ & $\begin{array}{l}80(66.5) \\
40(33.5)\end{array}$ & $\begin{array}{l}10(12.5) \\
70(87.5)\end{array}$ & 14.00 & $6.52-30.04$ & $<0.001$ \\
\hline Ever had education about their disease & $98(82)$ & $24(30)$ & 10.39 & $5.34-20.21$ & $<0.001$ \\
\hline Checking blood glucose daily & $64(53.5)$ & $44(55)$ & 1.01 & $0.57-1.79$ & 0.98 \\
\hline $\begin{array}{l}\text { Disease and therapy-related factors } \\
\text { Disease duration: } \\
\quad<5 \text { years } \\
>5 \text { years }\end{array}$ & $\begin{array}{l}77(64.5) \\
43(35.5)\end{array}$ & $\begin{array}{l}50(62.5) \\
30(37.5)\end{array}$ & 1.07 & $0.60-1.93$ & 0.81 \\
\hline $\begin{array}{l}\text { Number of medications } \\
\quad \leq 2 \\
\quad>2\end{array}$ & $\begin{array}{l}75(62.5) \\
45(37.5)\end{array}$ & $\begin{array}{l}32(40) \\
48(60)\end{array}$ & 2.5 & $1.40-4.47$ & $<0.001$ \\
\hline Suffering from other conditions & $75(62.5)$ & $70(87.5)$ & 0.24 & $0.11-0.51$ & $<0.001$ \\
\hline Experienced side effect & $72(60)$ & $65(81)$ & 0.35 & $0.18-0.68$ & $<0.001$ \\
\hline $\begin{array}{l}\text { Hospital admission due to blood glucose } \\
\text { level changing during the last year } \\
\quad 0-2 \text { times } \\
>2 \text { times }\end{array}$ & $\begin{array}{l}70(58) \\
50(42)\end{array}$ & $\begin{array}{l}42(52.5) \\
38(47.5)\end{array}$ & 1.27 & $0.72-2.24$ & 0.42 \\
\hline Taking alternative medicines & $30(25)$ & $68(85)$ & 0.06 & $0.03-0.12$ & $<0.001$ \\
\hline $\begin{array}{l}\text { Monthly medication cost } \\
\quad<300 \mathrm{AED}^{*}(=81.7 \$) \\
\geq 300 \mathrm{AED}(=81.7 \$)\end{array}$ & $\begin{array}{l}80(66) \\
40(34)\end{array}$ & $\begin{array}{c}5(6) \\
75(94)\end{array}$ & 30.0 & $11.2-80.1$ & $<0.001$ \\
\hline $\begin{array}{l}\text { Last } \mathrm{HbA1c} \text { reading } \\
\quad \geq 6.5 \\
\quad \leq 6.5\end{array}$ & $\begin{array}{l}75(62.5) \\
45(37.5)\end{array}$ & $\begin{array}{l}15(18.5) \\
65(81.5)\end{array}$ & 7.22 & $3.69-14.14$ & $<0.001$ \\
\hline $\begin{array}{l}\text { Health care- related factors } \\
\text { Stop taking medication because they fell } \\
\text { worse }\end{array}$ & $40(33.5)$ & $70(87.5)$ & 0.07 & $0.03-0.15$ & $<0.001$ \\
\hline $\begin{array}{l}\text { No. of times of medication was changed } \\
\text { by physician } \\
\text { Nil } \\
\geq 1\end{array}$ & $\begin{array}{l}69(57.5) \\
51(42.5)\end{array}$ & $\begin{array}{l}39(48.5) \\
41(51.5)\end{array}$ & 1.42 & $0.81-2.51$ & 0.22 \\
\hline Awareness of physician instructions & $75(62.5)$ & $15(18.5)$ & 7.22 & $3.7-14.1$ & $<0.001$ \\
\hline
\end{tabular}

${ }^{*} A E D$ (United Arab Emirates dirham) $=0.27$ US dollar 
monthly medications cost in AED (OR $=30.0, \mathrm{Cl}$ $=11.24-80.1)$ where the cost of three hundreds Emirati dirham or more (94 \%) had higher prevalence of non-adherence. Blood glucose control, $\mathrm{HbA} 1 \mathrm{c}$ were significantly associated with non-adherence $(\mathrm{OR}=7.22, \mathrm{Cl}=3.69-14.14)$ where high $\mathrm{HbA} 1 \mathrm{c}>6.5(81.5 \%)$ had higher risk of non-adherence. On the other hand, the patients who were taking two medications or less $(\mathrm{OR}=2.5, \mathrm{Cl}=1.40-4.47)$ had lower risk of non- adherence than the patients who were taking more than 2 medications. On the other hand the factors that were not significant were: disease duration and hospital admission due to blood glucose level changing during the last year (Table 3).

Among health care-related factors, the factors that were significantly associated with nonadherence: stop taking medications as they felt worse $(\mathrm{OR}=0.7, \mathrm{Cl}=0.03-0.15)$ and awareness of physician instructions $(\mathrm{OR}=7.22$, $\mathrm{Cl}=3.7-14.1$ ) where the patients who were not aware of physician instructions had higher prevalence of non-adherence (Table 3).

\section{DISCUSSION}

This study assessed the adherence level and the factors associated with non-adherence among type 2 diabetes patients in Northern Region of the UAE, and the adherence level to treatment was $60 \%$ while non-adherence was only $40 \%$. It is nearly similar to that found in a study conducted in India where the level of adherence was $57.7 \%$ [10]. Another similar study found that $41.7 \%$ of the patients did not adhere to their treatment [11]. However, a recent study in Malaysia found that the level of adherence was $47 \%$ [12]. A systemic review evaluating adherence found a range of 36 to $93 \%$ for antidiabetic medications [13]. The high level of adherence in the present study, which is depended on self-reports, was mainly because it may rely on patients own interpretation or memory and patients may tend to report higher levels of adherence in order to please health care providers or avoid embarrassment.

Among the demographic data, present study showed that adherence decreases with older age $(\geq 50)$ and in patients with no or primary education, but there were no significant association with gender and the marital status. Mukherjee et al from India [10] and Khan et al from Saudi Arabia [14] found similar results. However these studies $[10,14]$ reported that male sex had lower adherence rate, furthermore Khan et al [14] found no significant association between non adherence to antidiabetics and age.

As for monthly income, this study data corroborates the findings of other studies that reported that those with low monthly income showed lower adherence [10].

Regarding health insurance the patients who had no insurance had higher risk of non-adherence which is comparable with other study [15]. Insurance and free care may encourage more contact with health care system and can acts as a reminder for regular drug taking.

As for factors that affecting the adherence, patient-related factors such as forgetfulness was significant with non-adherence which was consistence with other studies $[10,16]$. The risk on non-adherence in this study increased among patient who had taken longer time since their last visit to the clinic which is comparable with other study [14].

In this study having health education sessions had higher prevalence of adherence. This is true when compared with another study [17]. Health education is an important component of diabetes type 2 management as it can improve patient knowledge and effect changes in behavior and lifestyle [17].

In regards to disease and therapy-related factors, in this study the risk of non-adherence increased with $\mathrm{HbA} 1 \mathrm{C}<6.5$ which is true with other study [18]. Therefore it is suggested that in patients with abnormal $\mathrm{HbA} 1 \mathrm{c}$ levels rather than increasing the prescribed dose, adding or replacing the prescribed drug, health providers should first assess patient adherence to medications [13].

Increased medication cost is crucial issue and it has been reported in this study as well other studies that the high cost of medications was significantly associated with non-adherence [5]. The total annual treatment costs of diabetic patients 3.2 higher than the per capita expenditure for health care in UAE and it is increased 2.2 times in the presence of complications [19], therefore anti-diabetic medication adherence plays a vital role in cost of diabetic care as non-adherence could lead to presence of complications and worsen the case. Presence of other co-morbidities with diabetes also had major impact on adherence where it had higher risk of non-adherence in this study. 
Similar conclusion has been drawn by other studies [12].

Taking alternative medicine was also one of the reasons of non-adherence in this study. Other studies also reported similar result $[10,20]$.

Suffering from medications side effects had significant association with non-adherence; similar conclusion has drowned by another study $[5,10]$.

This study resulted showed that increased medication number $>2$ had higher risk with nonadherence. Similar findings have obtained by a study done in Mosul [20]. The number of drugs taken by patients is dependent on the severity of T2DM and co-morbidities Thus; the drug regimen for patients with diabetes mellitus can become complex and adherence may definitely be a challenge for patients [5].

Diabetes duration had no association with adherence in this study; this is true with other study [12], while it's in contrast with another study finding [10].

Health care providers-related factors in this study have emerged as an important factor affecting patients' adherence. The patients who were not aware of physician instructions had higher risk of non-adherence which is comparable with other research [14]. When accurate and clear information on diabetes treatment is provided, patients could be encouraged toward self care and adherence to drug therapy. In this study majorities of the patients who had stopped their medication as they felt worse had higher nonadherence risk. Healthcare providers have the main responsibility for this critical finding as they should ask the patients about their medication in details and discuss everything about their therapy with them including all possible side effects which can make them feel worse.

\section{CONCLUSION}

The level of non-adherence to medications among type 2 diabetes patients was high. This may result in suboptimal outcomes of diabetes treatment. Several factors have been identified in this study as causative challenges for medication adherence. Identification of risk factors to nonadherence to treatment is fundamental before applying any treatment method for diabetic patients in order to conquer problem of nonadherence.

\section{Limitations of the study}

Some of the limitations of study were the possibility of inaccuracies in the responses of the patients that could be found in any self-reported questionnaire, especially for chronic diseases. There was always a chance of over-reporting of adherence.

\section{REFERENCES}

1. International Diabetes Federation. IDF Diabetes Atlas, 4th edn [Internet]. 2011 [cited 7 Jan 2013]. Available from: http://www. diabetesatlas.org.

2. Ciechanowski PS, Katon WJ, Russo JE, Walker EA. The patient-provider relationship: attachment theory and adherence to treatment in diabetes. Am J Psychiatry 2001; 158(1): 29-35.

3. Ho PM, Rumsfeld JS, Masoudi FA, McClure DL, Plomondon ME, Steiner JF, Magid DJ. Effect of medication nonadherence on hospitalization and mortality among patients with diabetes mellitus. Arch Intern Med 2006; 166(17): 1836-1841.

4. Rand CS. Measuring adherence with therapy for chronic diseases: implications for the treatment of heterozygous familial hypercholesterolemia. Am J Cardiol 1993; 72(10): 68-74.

5. Rubin RR. Adherence to pharmacologic therapy in patients with type 2 diabetes mellitus. Am J Med 2005; 118(Suppl): 27S-34S.

6. Afandi B, Ahmad S, Saadi H, Elkhumaidi S, Karkoukli MA, Kelly B, Assaf H, Marear D. Audit of a diabetes clinic at Tawam hospital, United Arab Emirates, 20042005. Ann N Y Acad Sci 2006; 1084: 319-324.

7. Alhyas L, McKay A, Balasanthiran A, Majeed A. Quality of type 2 diabetes management in the states of the Co-operation Council for the Arab States of the Gulf: A systematic review. PloS One 2011; 6(8): e22186.

8. Reed RL, Revel AO, Carter A, Saadi HF, Dunn EV. A clinical trial of chronic care diabetic clinics in general practice in the United Arab Emirates: A preliminary analysis. Arch Physiol Biochem 2001; 109(3): 272280.

9. Reed RL, Revel AD, Carter AO, Saadi HF, Dunn EV. A controlled before-after trial of structured diabetes care in primary health centres in a newly developed country. Int J Qual Health Care 2005; 17(4): $281-$ 286.

10. Mukherjee S, Sharmasarkar B, Das KK, Bhattacharyya A, Deb A. Compliance to anti-diabetic drugs: observations from the diabetic clinic of a medical college in Kolkata, India. J Clin Diagn Res 2013; 7(4): 661-665.

11. Chua SS, Chan SP. Medication adherence and achievement of glycaemic targets in ambulatory type 2 diabetic patients. J App Pharm Sci Journal of Applied Pharmaceutical Science, 2011; 1(4): 55-59. 
12. Ahmad NS, Ramli A, Islahudin F, Paraidathathu T. Medication adherence in patients with type 2 diabetes mellitus treated at primary health clinics in Malaysia. Patient Prefer Adherenc 2013; 7: 525-530.

13. Cramer JA. A Systematic Review of Adherence with Medications for Diabetes. Diabetes Care 2004; 27(5): 1218-1224.

14. Khan AR, Al-Abdul Lateef ZN, Al Aithan MA, BuKhamseen MA, Al Ibrahim I, Khan SA. Factors contributing to non-compliance among diabetics attending primary health centers in the Al Hasa district of Saudi Arabia. J Family Community Med 2012; 19(1): 26-32.

15. Pourghaznein T, Ghaffari $F$, Hasanzadeh $F$, Chamanzari $H$. The relationship between health beliefs and medication adherence in patients with type 2 diabetes: A correlation-cross sectional study. Life Sci J 2013; 10(5): 38-46.
16. Odegard PS, Carpinito G, Christensen DB. Medication adherence program: Adherence challenges and interventions in type 2 diabetes. J Am Pharm Assoc 2013; 53(3): 267-272.

17. Cooper HC, Booth K, Gill G. Patients' perspectives on diabetes health care education. Health Educ Res 2003; 18(2): 191-206.

18. Rozenfeld Y, Hunt JS, Plauschinat C, Wong KS. Oral antidiabetic medication adherence and glycemic control in managed care. Am J Manag Care 2008; 14(2): 71-75.

19. Al-Maskari F, El-Sadig M, Nagelkerke N. Assessment of the direct medical costs of diabetes mellitus and its complications in the United Arab Emirates. BMC Public Health 2010; 10(1): 679-689.

20. Al-Taee $W$. Non-compliance to treatment among type 2 diabetic men in Mosul: A case-control study. Ann Coll Med Mosul 2009; 35(2): 147-153. 